\title{
O cuidado ao idoso institucionalizado: perspectivas dos cuidadores e da equipe de enfermagem
}

\author{
Care for the institutionalized elderly: perspectives of the elderly caregiver and the nursing \\ team \\ El cuidado al anciano institucionalizado: perspectivas del cuidador de ancianos y del \\ equipo de enfermería
}

Clara Jéssica Silva Ferreira ${ }^{1}$, Dayse Bazílio Rosa de Souza ${ }^{1}$, Emily Christine de Souza ${ }^{1}$, Flávia de Oliveira $^{1}$, Kellen Rosa Coelho ${ }^{1 *}$.

\section{RESUMO}

Objetivo: Descrever o perfil dos profissionais de enfermagem e dos cuidadores de idosos institucionalizados e compreender o cuidado a esses idosos, na perspectiva desses profissionais. Métodos: Trata-se de um estudo exploratório-descritivo com abordagens quantitativa e qualitativa, desenvolvido com os profissionais de enfermagem e cuidadores de idosos institucionalizados em 5 Instituições de Longa Permanência para Idosos (ILPI's), localizadas no município de Divinópolis - Minas Gerais. Foram utilizados um questionário sociodemográfico e de condições de saúde e um roteiro semiestruturado para a coleta dos dados. Resultados: Participaram do estudo 36 profissionais responsáveis pelo cuidado aos idosos, majoritariamente caracterizados pelo sexo feminino, idade entre 31 e 49 anos, categoria profissional cuidadores de idosos e com boa condição de saúde autodeclarada. Emergiram duas categorias pela análise dos discursos: Cuidado ao idoso institucionalizado na visão do cuidador de idosos e da equipe de enfermagem e Fatores que influenciam no cuidado ao idoso institucionalizado. Conclusão: Permitiu compreender que o cuidado ao idoso institucionalizado provoca um misto de sentimentos no cotidiano do cuidar.

Palavras-chave: Enfermagem, Cuidadores, Idoso, Instituição de longa permanência para idosos.

\begin{abstract}
Objective: To describe the profile of nursing professionals and caregivers of institutionalized elderly people and to understand the care for these elderly people, from the perspective of these professionals. Methods: This is an exploratory-descriptive study with quantitative and qualitative approaches, developed with health professionals nursing and caregivers of institutionalized elderly in 5 Long Term Care Institutions for the Elderly (ILPI's), located in the municipality of Divinópolis - Minas Gerais. A sociodemographic and health conditions questionnaire and a semi-structured script were used to collect data. Results: 36 professionals responsible for the care of the elderly participated in the study, mostly characterized by the female gender, aged between 31 and 49 years, professional category caregivers of the elderly and with good self-declared health condition. Two categories emerged from the discourse analysis: Care for the institutionalized elderly in the view of the elderly caregiver and the nursing team and Factors that influence the care for the institutionalized elderly. Conclusion: It allowed us to understand that care for the institutionalized elderly causes a mix of feelings in daily life caring.
\end{abstract}

Keywords: Nursing, Caregivers, Elderly, Long term care institution for the elderly.

1 Universidade Federal de São João del Rei (UFSJ), Divinópolis - MG. *E-mail: kellencoelho@ufsj.edu.br

PUBLICADO EM: 5/2021 


\section{RESUMEN}

Objetivo: Describir el perfil de los profesionales de enfermería y cuidadores de personas mayores institucionalizadas y comprender el cuidado de estas personas mayores, desde la perspectiva de estos profesionales. Métodos: Se trata de un estudio exploratorio-descriptivo con abordajes cuantitativos y cualitativos, desarrollado con salud profesionales de enfermería y cuidadores de ancianos institucionalizados en 5 Instituciones de Atención de Larga Duración para Personas Mayores (ILPI's), ubicadas en el municipio de Divinópolis - Minas Gerais. Para la recogida de datos se utilizó un cuestionario sociodemográfico y de condiciones de salud y un guión semiestructurado. Resultados: Participaron en el estudio 36 profesionales responsables del cuidado del adulto mayor, caracterizados mayoritariamente por el género femenino, con edades comprendidas entre 31 y 49 años, categoría profesional cuidadores de ancianos y con buen estado de salud autodeclarado. Del análisis del discurso surgieron dos categorías: el cuidado del anciano institucionalizado en la mirada del cuidador del anciano y el equipo de enfermería y los factores que inciden en el cuidado del anciano institucionalizado. Conclusión: Permitió comprender que el cuidado del anciano institucionalizado provoca una mezcla de sentimientos en el cuidado de la vida diaria.

Palabras clave: Enfermería, Cuidadores, Ancianos, Institución de atención de larga duración para ancianos.

\section{INTRODUÇÃO}

A população idosa no Brasil vem aumentando aceleradamente no decorrer dos anos, com estimativa de atingir 25,5\% do total da população do Brasil em 2060 (IBGE, 2011; TAVARES RE, et al., 2017). Com esse aumento, cresce também o número de senis que necessitam de cuidados a longo prazo devido à ocorrência de eventos incapacitantes. Estes eventos podem diminuir o convívio social, interferir na qualidade de vida dos idosos e desestruturar a dinâmica familiar, podendo acarretar na institucionalização do idoso em ILPI's (BRASIL, 2016).

Além disso, existem idosos que possuem vínculos familiares rompidos, fragilizados ou não constituíram família e expressam o desejo de ir para uma instituição. Ainda, em caso de negligência e maus tratos, os idosos são institucionalizados como medida protetiva (FERREIRA H e PREUSS LT, 2017).

O perfil de saúde do idoso institucionalizado é composto por dependência funcional e, em maioria, por doenças cardiovasculares, seguido por doenças neurodegenerativas, diabetes mellitus e doenças psiquiátricas (ROSSATO V, 2017). Nesta perspectiva, os profissionais à frente do cuidado nas ILPI's devem assumir uma visão holística, pois o cuidar orienta-se para preencher as necessidades psicológicas, fisiológicas e sociais do idoso (ALMEIDA CAPL, et al., 2017). Sendo assim, existem basicamente duas categorias que atuam diretamente na assistência desta população, a equipe de enfermagem, composta por enfermeiros, técnicos e auxiliares de enfermagem e os cuidadores de idosos (MARIANO PP, et al., 2015).

O cuidado ao idoso é uma atividade bastante estressante. Este evento, associado à capacitação inadequada e ao elevado número de idosos para cuidar, gera um desgaste físico, emocional e psicológico no profissional que está na assistência direta, e que muitas vezes acarreta um estado de esgotamento, sobrecarga de trabalho e diminuição da qualidade de vida. Vale ressaltar que tais condições ocasionam prejuízos na assistência, fazendo com que o idoso não seja assistido de forma integral e efetiva (ALVES EVC, et al., 2018).

Em contrapartida, mesmo sendo uma atividade bastante complexa, especialmente devido à execução da rotina de cuidados diários, cuidar de idosos institucionalizados pode trazer para os profissionais sentimentos de satisfação, gratidão e de vínculo familiar. O relacionamento entre o cuidador e o idoso está imbuído de subjetividade que, quando se é positivo, este se permeia por sentimentos de gratidão, amor, carinho e atenção, o que possibilita a efetivação do cuidado holístico e humanizado (ALMEIDA CAPL, et al., 2017).

Frente a esse contexto e ao atual crescimento acelerado da população idosa, o que reflete no aumento da demanda por ILPI's, conhecer o perfil e a visão dos profissionais sobre o cuidado ao idoso 
institucionalizado ainda representa um desafio para a prática em saúde gerontológica. Destarte, torna-se relevante investigar como se configura este cuidado, bem como os desafios e potencialidades que os profissionais da enfermagem e os cuidadores de idosos enfrentam em seus cotidianos de cuidado. Informações advindas desta investigação podem evidenciar subsídios para a reflexão e discussão de estratégias para a melhoria do processo de trabalho nas ILPI's, bem como da saúde e qualidade de vida destes profissionais e, consequentemente, na melhoria da assistência aos idosos institucionalizados (ALMEIDA CAPL, et al., 2017).

Dessa forma, o objetivo deste estudo foi descrever o perfil dos profissionais de enfermagem e dos cuidadores de idosos institucionalizados, bem como compreender o cuidado a esses idosos, na perspectiva desses profissionais.

\section{MÉTODOS}

Trata-se de um estudo exploratório-descritivo com abordagens quantitativa e qualitativa, desenvolvido com profissionais de enfermagem e cuidadores de idosos institucionalizados em 5 ILPI's, localizadas em um município do interior de Minas Gerais. Dentre estas ILPI's duas eram filantrópicas e três privadas. Considerou-se como embasamento teórico a Teoria das Representações Sociais (MOSCOVICI S, 2009).

A amostra do estudo foi proposta para todos os cuidadores e profissionais de enfermagem que cuidam de idosos institucionalizados no município, total de 70 profissionais. Entretanto, uma ILPI recusou o estudo e em outra a coleta de dados não pôde ser realizada devido ao início da pandemia de COVID-19 no Brasil, momento em que as entrevistas precisaram ser interrompidas. Portanto, a amostra foi por conveniência e contou com 36 cuidadores e profissionais de enfermagem. Os critérios de inclusão foram: ter idade superior a 18 anos e trabalhar na ILPI por no mínimo seis meses. O critério de exclusão foi o profissional estar de férias ou de licença no momento da entrevista.

Os dados foram coletados entre setembro/2019 e fevereiro/2020, por meio de entrevistas nas instituições, de forma individual e com privacidade. Foram utilizados dois instrumentos: (1) questionário estruturado sobre o perfil sociodemográfico e condições de saúde, (2) roteiro semiestruturado partindo da questão norteadora: "Para você, como é cuidar do idoso institucionalizado?". Cada entrevista durou 20 minutos e foi gravada com consentimento do participante. As gravações foram transcritas na íntegra.

Para o agendamento das entrevistas, a equipe entrou em contato com a direção de cada instituição e com os cuidadores e os profissionais da enfermagem, posteriormente. Antes de cada entrevista, o participante era esclarecido sobre objetivos e procedimentos da pesquisa. Respeitou-se o anonimato dos participantes identificando-os pelas letras E, T ou C (Enfermeiro, Técnico ou Cuidador) e números pela ordem de entrevista.

Vale salientar que, apesar de não ter sido possível entrevistar o universo total de profissionais à frente do cuidado aos idosos institucionalizados no município, foi observado que as entrevistas realizadas atingiram a saturação dos dados, garantindo a validade da amostra.

Em relação à organização e análise descritiva dos dados quantitativos, estas foram realizadas no programa Epi Info versão 7.2.3.1, com o cálculo das frequências absolutas e relativas para caracterização dos participantes. Para analisar os dados qualitativos, foi utilizada a análise de conteúdo do tipo temática (BARDIN L, 2011).

O estudo foi submetido ao Comitê de Ética em Pesquisa com Seres Humanos da instituição proponente, com parecer 3.399.532 e Certificado de Apresentação para Apreciação Ética 14113819.2.0000.5545. Todo processo de pesquisa e utilização dos dados seguiram os termos da Resolução no 466 de 2012 do Conselho Nacional de Saúde e todos os participantes assinaram o Termo de Consentimento Livre e Esclarecido. Este estudo foi conduzido de acordo com as diretrizes do Consolidated Criteria for Reporting Qualitative Research (COREQ). 


\section{RESULTADOS}

Participaram do estudo 36 profissionais responsáveis pelo cuidado direto aos idosos institucionalizados, distribuídos entre as categorias profissionais: $23(63,9 \%)$ cuidadores de idosos, $11(30,6 \%)$ técnicos de enfermagem e $2(5,5 \%)$ enfermeiros. A maioria destes profissionais é composta por mulheres $34(94,4 \%)$, solteiras $16(44,4 \%)$, católicas $26(72,2 \%)$, de cor autodeclarada branca ou parda $29(80,4 \%)$, com idade entre 31 e 49 anos 23 (63,9\%), com nível de escolaridade ensino médio completo 19 (52,8\%), possuíam pelo menos um filho $28(77,8 \%)$ e residiam na zona urbana do mesmo município das ILPI's $34(94,4 \%)$ (Tabela 1).

Tabela 1 - Caracterização dos participantes em relação à categoria profissional, ao sexo, ao estado civil, à religião, à cor, à idade, ao número de filhos e ao local da residência, $n=36$. Divinópolis-MG, 2020.

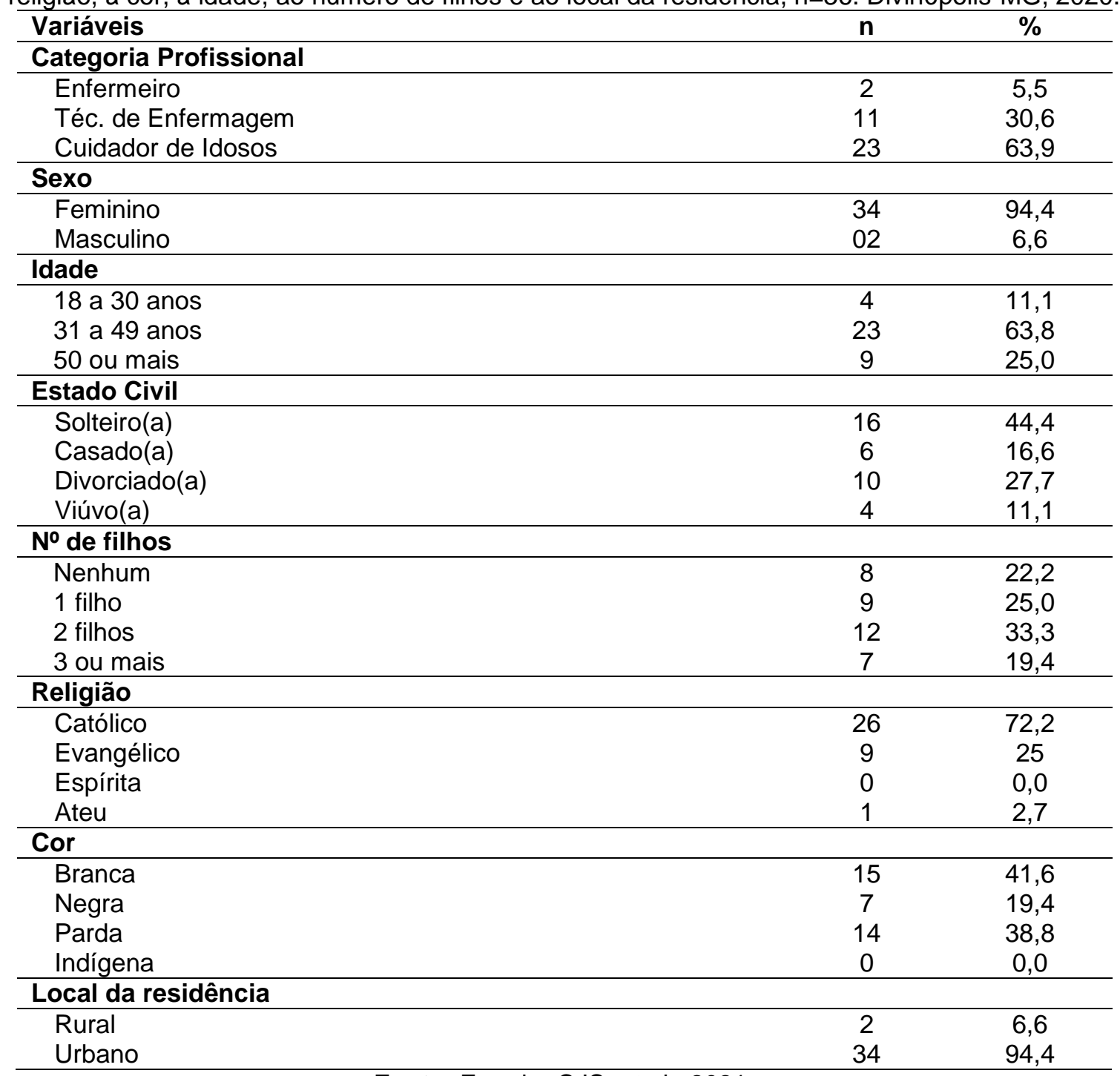

Fonte: Ferreira CJS, et al., 2021.

Em relação à condição de saúde, a maioria dos cuidadores de idosos e profissionais da enfermagem avaliaram a própria saúde como boa ou muito boa $25(69,4 \%)$, apenas $3(8,3 \%)$ possuíam diabetes ou doenças cardiovasculares e $21(58,3 \%)$ não faziam uso nenhum medicamento de uso constante. Ainda, 18 $(50,0 \%)$ dos cuidadores informaram que nunca fizeram cirurgia e $19(52,8 \%)$ nunca precisaram ser internados. Vale ressaltar que $17(47,2 \%)$ possuíam acesso à saúde suplementar (plano de saúde privado) (Tabela 2). 
Tabela 2 - Caracterização dos participantes em relação às condições de saúde, às doenças crônicas, ao uso de medicamentos, à realização de cirurgia, à internação e ao plano de saúde, $\mathrm{n}=36$. Divinópolis-MG, 2020.

\begin{tabular}{|c|c|c|}
\hline Variáveis & $\mathbf{n}$ & $\%$ \\
\hline \multicolumn{3}{|l|}{ Condição de Saúde } \\
\hline Muito boa & 7 & 19,4 \\
\hline Boa & 18 & 50,0 \\
\hline Regular & 10 & 27,7 \\
\hline Ruim & 1 & 2,7 \\
\hline Muito ruim & 0 & 0,0 \\
\hline \multicolumn{3}{|l|}{ Doenças Crônicas } \\
\hline Nenhuma & 28 & 77,7 \\
\hline Doenças Cardiovasculares & 1 & 2,7 \\
\hline Diabetes Mellitus & 2 & 5,5 \\
\hline Câncer & 0 & 0,0 \\
\hline Outras & 0 & 0,0 \\
\hline \multicolumn{3}{|l|}{ Medicamentos } \\
\hline Não & 21 & 58,3 \\
\hline Sim, 1 & 8 & 22,2 \\
\hline Sim, 2 & 4 & 11,1 \\
\hline Sim, 3 ou mais & 3 & 8,3 \\
\hline \multicolumn{3}{|l|}{ Cirurgia } \\
\hline Já realizou & 18 & 50,0 \\
\hline Nunca realizou & 18 & 50,0 \\
\hline \multicolumn{3}{|l|}{ Internação } \\
\hline Já precisou & 17 & 47,2 \\
\hline Nunca precisou & 19 & 52,7 \\
\hline \multicolumn{3}{|l|}{ Plano de Saúde } \\
\hline Possui & 17 & 47,2 \\
\hline Não possui & 19 & 52,8 \\
\hline
\end{tabular}

Fonte: Ferreira CJS, et al., 2021.

No concernente à abordagem qualitativa do estudo, a análise temática das entrevistas evidenciou duas categorias: O cuidado ao idoso institucionalizado na visão do cuidador de idosos e de profissionais da enfermagem e Fatores que influenciam no cuidado ao idoso institucionalizado.

\section{O cuidado ao idoso institucionalizado na visão do cuidador de idosos e de profissionais da enfermagem}

O cuidado ao institucionalizado na visão dos profissionais que estão à frente deste ofício é marcado por sentimentos de gratidão, amor, carinho, felicidade, empatia, compaixão e satisfação. Estes sentimentos são emergidos ao reconhecerem nos idosos, a realização dos cuidados prestados:

"Ah eu me sinto muito gratificante, não por causa do salário, mas... ah! É um amor grande que eu tenho entendeu?" (T9).

"Eu gosto! Sinto prazer, amor. Quando eu tô aqui, nó, eu esqueço os problemas tudo lá fora" (C9).

"Gosto muito de trabalhar nessa área... sinto muito acolhida por eles, sabe? Eu acho que é uma idade que eles precisam de carinho e... nós proporcionamos isso pra eles né, com todo prazer" (C8).

Por vezes, estes sentimentos de afeto criam vínculos fortes e transcendem para a esfera familiar, em que se percebe no discurso o desenvolvimento de sentimentos pela prestação de cuidados aos idosos assim como se tem com uma pessoa de laços consanguíneos: 
"Pra mim cuidar do idoso é como se fosse cuidar de alguém da família, tem que ter amor, tem que ter carinho, se não tiver, não dá" (C9).

"A gente apega muito neles, né? Porque assim, eles gostam da gente a troco de um nada, um amor puro, verdadeiro que eles sentem pela gente e a gente por eles, né?" (C10).

Aliado a isso, os profissionais evidenciam a importância do exercício da escuta e de manter o diálogo, relatam que aprendem muito com as histórias de vida dos mais velhos que na cultura popular, não são valorizados:

"A gente acaba aprendendo com eles também né? Como tem alguns lúcidos a gente acaba dialogando bastante, conversando, cria um... vínculo, principalmente quando é mais lúcido, a gente conversa, é muito bacana" (E1).

"E ouvir as histórias deles, a história de vida porque cada dia é um aprendizado a mais e você cuidar de idoso você aprende mais a valorizar a vida" (C11).

Em contrapartida, com a exacerbação dos sentimentos e da fragilidade que o cuidado ao idoso representa, os profissionais reforçam em seus discursos o estereótipo de que o idoso "se parece com criança", o cuidado prestado é infantilizado e está representado nos seguintes trechos:

"Olha, eu acho que o cuidado com o idoso é como se você cuidasse da sua criança, né? Porque se você não tem uma... paciência, uma... como eu vou falar... um zelo, um cuidado, você não pode ser um cuidador, né? Então assim, a pessoa exige muito da gente igualzinho como se fosse uma criança mesmo" (T6).

"Igual a uma criança, né? Cuidar direitinho, tem que ter paciência, se não tiver não precisa nem entrar nessa área não porque tem que ter muita paciência, idoso é criança, pra trabalhar nessa área tem que ter a maior paciência" (C13).

Percebe-se que também existe uma dificuldade velada no cuidado ao idoso institucionalizado, os profissionais destacam que é preciso ter preparação, paciência, atenção e responsabilidade para lidar com o trabalho cansativo:

"Olha, éé... Você tem que ter muita paciência, assim, é uma responsabilidade muito grande, né?[...] É cansativo, porque eu trabalho com uma média de 25, então cada um acorda de um jeito, com o humor, uns tá triste, outros estão agressivos, outros querem atenção, então você tem que ter paciência" (C18).

"Eu acho que a maior dificuldade é essa mesmo, a questão de você tá assim com paciência mesmo pra cuidar, né? Porque tem dia que eles te xingam, eles brigam com a gente, a gente tem que ter aquela paciência mesmo, né? Porque tem que ouvir e ficar calada. (risos)" (C18).

\section{Fatores que influenciam no cuidado ao idoso institucionalizado}

O grau de dependência do idoso, seja de ordem cognitiva ou mobilidade, foi considerado como um fator que traz maior dificuldade no manejo do cuidado nas ILPI's, sobretudo pela demanda excessiva de atenção por parte dos profissionais:

"Existe a dificuldade com os que tem demência, Alzheimer, essas coisas, esquecem de engolir, mastigar... mas com jeitinho a gente vai... Igual, tem a questão de engolir o remédio, ficar com o alimento na boca, tem que ter muita atenção pra eles não engasgarem né?" (T4).

"Os mais acamados, eles demandam mais tempo, sozinho não dá não..." (C9). 
"A dificuldade que eu tenho é de pegar alguns, igual aquela que estava sentada ali por exemplo eu não consigo, porque ela é muito rígida e infelizmente eu não tenho força pra pegar. Então às vezes eu tenho dificuldade pra pegar sozinha um idoso e tanto é que eu nem faço, eu vejo dificuldade, eu chamo pra me ajudar" (T6).

A rotina com as atividades de vida diária e com a administração de medicamentos também foi um fator mencionado como demanda importante no cuidado aos idosos institucionalizados:

“Uai, a gente tem que respeitar eles né? Auxiliar no banho, na alimentação, né? Esses cuidados" (C6).

"A gente assim, dá o banho, dá o alimento, a gente troca as fraldas, a gente administra medicamento, aplica insulina, administra dieta, eu não tenho dificuldade não, eu gosto disso. Então, às vezes a gente recebe um paciente mais idoso que tem a questão do peso, então pra mim é mais difícil, muito complicado, né?" (T8).

Outro fator que interfere no cuidado, segundo os profissionais do estudo, é a carência afetiva dos idosos, principalmente por se sentirem muito sozinhos e longe da família. Essa carência é percebida, mas nem sempre pode ser atendida de acordo com as expectativas devido, sobretudo, à falta de tempo:

"Assim tem horas que... eles querem atenção... tipo assim, eles querem que você senta lá no quarto, quer que você fica, aí tem hora que o tempo tá meio corrido. E isso me corta o coração, sabe? Eles arrumam um pretexto no quarto só pra você ir lá, pra eles te ver você lá... quer é atenção. Aí eu queria ter mais tempo, sabe? Você vai dar medicamento, você está com a bandeja cheia de medicamento, aí ele quer te contar tudo o que aconteceu pra você e sem tempo, eu morro de dó" (T3).

“...muitas das vezes não recebe visita de familiares, muita das vezes passa muito tempo um parente sem vir visitar e muita das vezes eles estão carentes apenas de um abraço, de um bom dia, boa tarde, uma palavra amiga" (T9).

"[...] São muito deprimidos né? Tristes e tem uns que fica esperando a família chegar e não chega. Aí além de ser cuidadora você tem que usar um pouquinho da psicologia pra acalentar o idoso, né? Porque você faz mais parte da vida deles pra eles do que os filhos, do que os parentes" (C20).

Segundo os profissionais do estudo, o trabalho em equipe também influencia no cuidado e é fundamental para o desenvolvimento das atividades com os idosos de forma mais leve e cooperativa:

"A facilidade é o companheirismo dos colegas né? Porque a gente trabalha com duas pessoas ou mais, porque um sozinho é cansativo" (T2).

"Óh, a facilidade que a gente tem é trabalhar em equipe, porque uma andorinha sozinha não levanta vôo. Então, como se diz, você tem que preparar sua equipe, pra ter aquele feedback, aquele retorno, entendeu? Então quando você está com a equipe boa tudo flui" (E2).

"Porque assim, dificuldade tem quando você vai fazer alguma coisa sozinho, tirar uma pessoa da cama sozinho é difícil, mas quando tem uma pessoa pra te ajudar, no caso a gente trabalha de duas, então uma auxilia a outra" (C16).

\section{DISCUSSÃO}

O perfil dos cuidadores de idosos e dos profissionais de enfermagem à frente do cuidado nas ILPI's do estudo, sobretudo no que diz respeito ao sexo feminino e à escolaridade/formação profissional de nível médio, vai de encontro ao perfil encontrado em outros cenários. Historicamente a mulher tem sua função designada ao papel do cuidador principal das tarefas da casa e dos filhos, no ambiente familiar ou profissional. Quanto ao nível de escolaridade e a formação profissional, embora o baixo nível de formação 
permita a execução do serviço de forma efetiva, ainda assim, há necessidade de aprimoramento do conhecimento, por meio de cursos e capacitações, para que seja garantida a qualidade do serviço prestado (ALMEIDA CAPL, et al., 2017; LIMA RJ, et al., 2016; BARBOSA LM, 2017).

No tocante à autoavaliação dos cuidadores e profissionais de enfermagem sobre a própria saúde, o que se observou foi uma visão otimista sobre sua própria saúde. Entretanto, há de se considerar que a rotina de cuidados com os idosos institucionalizados pode causar sobrecarga de trabalho e prejuízo à qualidade de vida destes profissionais, o que consequentemente pode repercutir na condição de saúde dos mesmos. De fato, o cuidado prestado a um idoso dependente institucionalizado, com a rotina de trabalho com cuidados diários, como alimentação e medicação, gravidade da doença e as complexidades no entorno dessa função estão associados ao nível de sobrecarga de trabalho e a qualidade de vida do cuidador formal (BALLARIN MLGS, et al., 2016).

Em relação à percepção que os profissionais do estudo têm do cuidado com os idosos institucionalizados, os discursos evidenciaram a importância da escuta e do diálogo para a relação harmoniosa entre cuidador e idoso, em que por meio destes é que emergem os sentimentos de amor, carinho, afeto e atenção pelo idoso. Muitas vezes, na rotina de cuidados, o idoso institucionalizado estabelece vínculos com seu cuidador responsável, compartilhando experiências, intimidades, anseios e angústias. Isso ocorre devido ao longo período de convivência e ao suporte emocional ofertado pelos profissionais que, por sua vez, destacam a importância desta escuta na consequente construção dos sentimentos positivos, importantes na manutenção da convivência amorosa e afetuosa na instituição (CERUTTI P, et al., 2019).

Outro ponto observado foi o cuidado prestado ao idoso mencionado nos discursos dos participantes do estudo como uma relação infantilizada. Esta relação pode ser explicada pelo fato de os cuidadores deterem o poder e o controle sobre as ações diárias e isso faz com que os idosos estejam em posição submissa e passiva no cuidado, equiparando à relação entre pais e filhos pequenos. Esta relação se torna um ciclo vicioso, visto que os cuidadores e as instituições entendem que os idosos estão sobre seus cuidados e, devido a fatores de saúde que os impedem de decidir por si mesmos, assumem o idoso como uma pessoa "dócil, submissa e conformada" (SANTOS RAAS, et al., 2016).

Sentimentos geradores de sofrimento nos profissionais à frente do cuidado ao idoso institucionalizado também foram mencionados pelos participantes do estudo, dentre eles, o fato do idoso sentir a ausência da família e o desinteresse desta para com o seu idoso. Tal fato faz com que o cuidador se torne a única referência de afeto do idoso e, muitas vezes, por não conseguir trazer resolutividade para esta falta, o cuidador se vê em sofrimento. Outra situação constante no cotidiano dos profissionais das ILPI's e que gera consternação é acompanhar o declínio funcional e a piora clínica dos idosos, pois, se o prazer é consequência do cuidado prestado de forma efetiva, quando o cuidado prestado não é mais capaz de manter a estabilidade do idoso, consequentemente, diminui sua satisfação laboral (MARIANO PP e CARREIRA L, 2016).

Aliado a estas angústias, os cuidadores do presente estudo relataram enfrentar diversos desafios no que diz respeito à demanda excessiva de cuidados, sobretudo na rotina com os idosos que possuem algum grau de dependência funcional. Diante desses percalços, o trabalho torna a função cansativa, esgotante e difícil, causando sobrecarga física e mental, a diminuição da qualidade do serviço prestado e a insatisfação profissional (MARIANO PP e CARREIRA L, 2016).

Para além do preparo técnico, do ponto de vista de atualizações/capacitações na área, estes profissionais precisam estar preparados emocionalmente e psicologicamente para enfrentar as adversidades inerentes do trabalho nas ILPI's. Este fortalecimento tanto profissional, quanto psíquico do cuidador pode repercutir diretamente no cuidado, no que diz respeito à mitigação da sobrecarga de trabalho e também da melhora da qualidade da assistência prestada aos idosos (ALBUQUERQUE TMO, 2017; DAMACENO DG, 2019).

Outro aspecto que foi mencionado no estudo e que impacta no cuidado aos idosos é o trabalho em equipe nas ILPI's. Segundo os participantes do presente estudo e também de outros cenários, a boa 
convivência e a cooperação entre os profissionais durante o cuidado aos idosos institucionalizados pode se tornar uma alternativa para minimizar as dificuldades do trabalho e potencializar a melhoria no cuidado aos idosos (LACCORT AA e OLIVEIRA GB, 2017; SOUZA GC, et al., 2016).

Como limitação do estudo, tem-se o fato da interrupção da coleta de dados devido ao início da pandemia de COVID-19 ter impedido a equipe da pesquisa entrevistar todos os profissionais à frente do cuidado nas ILPI's participantes do estudo. Mas, embora não tenha sido possível que todos os profissionais participassem, ainda assim, o presente estudo contribui para o conhecimento em saúde, sobretudo no contexto da enfermagem gerontológica, na medida em que fornece subsídios para uma melhor compreensão e reflexão das relações de cuidado aos idosos institucionalizados na visão dos profissionais responsáveis por este cuidado, colaborando para o aperfeiçoamento das relações afetivas e da assistência prestada aos idosos.

\section{CONCLUSÃO}

$\mathrm{Na}$ perspectiva dos cuidadores de idosos e dos profissionais da enfermagem das ILPI's, o estudo permitiu compreender que o cuidado ao idoso institucionalizado provoca um misto de sentimentos no cotidiano do cuidar, ora de satisfação, gratidão e felicidade por criarem vínculos de afeto com os idosos, ora de sofrimento por não conseguirem suprir toda a demanda afetiva e por acompanharem o declínio funcional dos idosos. Ademais, vale ressaltar que para os profissionais do estudo a dependência funcional do idoso institucionalizado gera demanda excessiva e exaustiva de cuidado, mas em contrapartida, o trabalho em equipe torna a rotina do cuidado mais leve e cooperativa.

\section{REFERÊNCIAS}

1. ALBUQUERQUE TMO, et al. A implementação de metodologias ativas para capacitação dos cuidadores informais de idosos. Realize Editora, 2017.

2. ALMEIDA CAPL, et al. A visão de cuidadores no cuidado de idosos dependentes institucionalizados. Estud. interdiscipl. envelhec., 2017; 22(1): 145-161.

3. ALVES EVC, et al. A dupla vulnerabilidade de idosos cuidadores: Multimorbidade e sobrecarga percebida e suas associações com fragilidade. Rev. bras. geriatr. gerontol., 2018; 21: 3.

4. BALLARIN MLGS, et al. Perfil sociodemográfco e sobrecarga de cuidadores informais de pacientes assistidos em ambulatório de terapia ocupacional. Cadernos Brasileiros de Terapia Ocupacional, 2016; 24(2): 315-321.

5. BARBOSA LM, et al. Qualidade de vida relacionada à saúde dos cuidadores formais de idosos institucionalizados em Natal,Rio Grande do Norte. Rev. Bras. Est. Pop., 2017.

6. BARDIN L. Análise de conteúdo. Edição 70, 2011.

7. BRASIL. Agência Nacional de Saúde Suplementar. Idoso na saúde suplementar: uma urgência para a saúde da sociedade e para a sustentabilidade do setor. 2016.

8. CERUTTI P, et al. O trabalho dos cuidadores de idosos na perspectiva da economia do care. Revista Eletrônica Espaço Tema Livre, 2019.

9. DAMACENO DG, et al. A Prática do Cuidado em Instituições de Longa Permanência para Idosos: desafio na formação dos profissionais. Rev. Bras. Geriatr. Gerontol., 2019; 22(1): e180197.

10. FERREIRA H, PREUSS LT. Motivos que levam as famílias e as pessoas idosas buscarem por vaga em Instituição de Longa Permanência para Idosos no Município de Ponta Grossa - Paraná. Il Congresso Internacional de Política Social e Serviço Social: Desafios Contemporâneos, 2017.

11. IBGE. INSTITUTO BRASILEIRO DE GEOGRAFIA E ESTATÍSTICA. 2018. Projeção da população em 2018: número de habitantes do país deve parar de crescer em 2047. Agência IBGE.

12. LACCORT AA, OLIVEIRA GB. A Importância do Trabalho em Equipe no Contexto da Enfermagem. Revista Uningá Review, 2017; 29(3).

13. LIMA RJ, et al. Profile of Care giver of Institutionalized Elders. International Archives of Medicine, $2016 ; 9$.

14. MARIANO PP, CARREIRA L. Prazer e sofrimento no cuidado ao idoso em instituição de longa permanência: percepção dos trabalhadores de enfermagem. Esc. Anna Nery, 2016; 20(4): e20160088.

15. MARIANO PP, et al. Organização do Trabalho de Enfermagem nas Instituições de Longa Permanência para Idosos: relação com o prazer e sofrimento laboral. Texto Contexto Enferm., 2015.

16. MOSCOVICI S. Representações Sociais: Investigações em Psicologia Social. 6 ed. Petrópolis: Vozes, 2009.

17. ROSSATO V, et al. Doenças Pregressas e Atuais de Idosos Institucionalizados em Lar de Longa Permanência Identificadas na Assistência em Saúde. Universidade Cruz Alta - UNICRUZ, 2017.

18. SANTOS RAAS, et al. Atenção no Cuidado ao Idoso: infantilização e desrespeito à autonomia na assistência de enfermagem. Rev. Pesq. Saúde, 2016; 17(3): 179-183.

19. SOUZA GC, et al. Trabalho em Equipe de Enfermagem: circunscrito à profissão ou colaboração interprofissional? Revista da Escola de Enfermagem da USP, 2016.

20. TAVARES RE, et al. Envelhecimento saudável na perspectiva de idosos: uma revisão integrativa. Rev. Bras. Geriatr. Gerontol., 2017. 